\title{
MICROGYNE MARCHESIANA (ASTERACEAE: ASTEREAE) NOVA OCORRÊNCIA PARA A FLORA DO BRASIL ${ }^{1}$ \\ BARBARA PINHEIRO MOREIRA² ANABELA SILVEIRA DE OLIVEIRA DEBLE ${ }^{3}$ LEONARDO PAZ DEBLE ${ }^{4}$
}

\section{RESUMO}

A família Asteraceae está distribuída em todos os continentes do mundo, com exceção da Antártida e reúne cerca de 30.000 espécies nos dois hemisférios. Com objetivo de catalogar as espécies desta importante família há um esforço para registrar os táxons ocorrentes na flora brasileira. O trabalho foi elaborado através de revisão bibliográfica e coletas feitas no Cerro Chato, em Santana do Livramento. Também foram realizadas excursões de coleta em prováveis locais de ocorrência de Microgyne Marchesiana, nas regiões fisiográficas da Campanha e Serra do Sudeste. Os indivíduos coletados foram georreferenciados, fotografados e identificados através de consulta bibliográfica. O material coletado foi anexado ao Herbário da Unipampa, campus Dom Pedrito. Microgyne Marchesiana foi coletada na localidade de Cerro Chato, no município de Santana do Livramento. Trata-se de uma espécie típica de afloramentos rochosos; as populações possuem escassos indivíduos, que crescem em fissuras de rochas de origem vulcânica. A distribuição geográfica é inferior a $1000 \mathrm{~km}^{2}$; as populações contêm poucos indivíduos e têm habitat especializado, pois ocorrem exclusivamente em fendas de afloramentos rochosos. De acordo com os critérios da IUCN, a espécie deve ser considerada como "Em Perigo".

Palavras chave: conservação, distribuição geográfica, Podocominae, táxon.

\begin{abstract}
[Microgyne Marchesiana (Asteraceae: Astereae) a new record from the Brazilian Flora].

The Asteraceae Family occurs in all continents except Antarctic, and comprises the largest family in number of species with ca. of 30,000 taxa in both hemispheres. Aiming to catalog the species of this important Family there is an effort to record species of the Brazilian flora. The work was developed by bibliographic review and vouchers made in the locality of Cerro Chato, Santana do Livramento municipality, Rio Grande do Sul state. Sampling was also conducted in presumable places of occurrence in the physiographic regions of Campanha and Serra do Sudeste. The collected specimens were geo-referenced, photographed, and the voucher specimens were deposited in the Unipampa Herbarium. Microgyne Marchesiana was found in the locality of Cerro Chato, Santana do Livramento municipality. Microgyne Marchesiana is typical of volcanic rocks; the populations are composed by few individuals, which grow on cracks, among volcanic rocks. The geographic distribution is smaller than $1,000 \mathrm{~km}^{2}$; the populations contains few individuals and grow in high specialized habitat, since they occurs exclusively in cracks of rocky outcrops. According with IUCN criteria, Microgyne Marchesiana should be treated as "Endangered Species".

Palavras chave: conservation, geographic distribution, Podocominae, taxon.
\end{abstract}

${ }^{1}$ Recebido em 05/03/2016 e aceito para publicação em $19 / 04 / 2016$.

${ }^{2}$ Zootecnista, Universidade Federal do Pampa, Unipampa, Campus de Dom Pedrito. barbara_pinheiro2008@hotmail.com

${ }^{3}$ Bióloga, Dra. Prof. da Universidade da Região da Campanha, campus Dom Pedrito, RS.

${ }^{4}$ Biólogo, Dr. Prof., Universidade Federal do Pampa, Unipampa, campus Dom Pedrito, RS. 


\section{INTRODUÇÃO}

A família Asteraceae inclui 555 espécies na flora sul-rio-grandense, sendo a família botânica mais bem representada neste estado (Deble \& Oliveira-Deble, 2011). Para o Bioma Pampa são reportados 435 táxones, ocorrentes principalmente em áreas abertas (Oliveira-Deble \& Deble, 2012). A tribo Astereae é o grupo mais numeroso na flora nativa do Rio Grande do Sul, com 137 entidades taxonômicas, distribuídas em 15 gêneros. No Bioma Pampa, 105 espécies dessa tribo são conhecidas como autóctones (Oliveira-Deble \& Deble, 2012).

Microgyne Less. (Astereae: Podocominae) possui distribuição geográfica restrita ao centro-sul da América do Sul, e inclui ervas perenes, com tricomas lanosos e glandulares, folhas de contorno oblanceolado, trifurcadas até pinatífidas, capítulos solitários, com brácteas involucrais dispostas em 2-4 séries, e flores heteromorfas; as marginais, pistiladas, com corola estreitamente tubular de ápice ligulado, e as do disco, perfeitas, de corola tubular, 5denteadas em sua parte distal. As cipselas, por sua vez, são turbinadas e densamente seríceopubescentes (recobertas por tricomas gêmeos) e o papilho barbelado ou escabroso, disposto em 2-séries (Nesom, 1994; Sancho et al., 2006).

Diversos autores (Bentham, 1867; Bentham \& Hooker, 1873; Baker, 1882; Arechavaleta 1908; Cabrera, 1974) reconheceram Microgyne como sinonímia de Vittadinia A. Rich, gênero com distribuição geográfica restrita à Oceania. Posteriormente, Microgyne trifurcata Less., única espécie sul-americana conhecida na época, foi tratada por Grau (1975) sob o nome ilegítimo de Microgynella Grau. Recentemente, Sancho et al. (2006) realizaram a revisão do gênero e reestabeleceram o nome Mycrogyne como válido, além de descrever Mycrogyne Marchesiana, considerada exclusiva do Uruguai, crescendo na localidade de Cuchilla de Laureles, no departamento de Tacuarembó, distante cerca de $40 \mathrm{~km}$ da fronteira com o Brasil.

Excursões de coleta na localidade do Cerro Chato, realizadas entre 2012 e 2013 , evidencia- ram a ocorrência de duas populações de Microgyne Marchesiana nativas no Brasil. Outras tentativas de localizar a espécie foram realizadas nas regiões da Campanha e Serra do Sudeste, todavia a espécie não foi novamente encontrada. Neste estudo, fotos, ilustrações e mapa atualizado da distribuição geográfica da espécie são fornecidos, sendo inferidas informações referentes à conservação, habitat, fenologia e distinção da outra espécie do gênero.

\section{MATERIAL E MÉTODOS}

Foram realizadas excursões de coleta em prováveis locais de ocorrência de Microgyne Marchesiana, nas regiões fisiográficas da Campanha e Serra do Sudeste (Fortes, 1979). Os indivíduos coletados foram georreferenciados, fotografados e identificados através de consulta bibliográfica. As coletas foram depositadas no Herbário da Unipampa, campus Dom Pedrito, para fins de registro. Visando à complementação de dados referentes à distribuição geográfica e o status de conservação da espécie estudada, foram analisadas exsicatas dos seguintes herbários: CTES, HAS, HBR, FLOR, ICN, MVM, MVFA, PACA e SI (Thiers, 2014); no entanto, não foram encontradas coletas adicionais àquelas já mencionadas no protólogo da espécie (Sancho et al. 2006: 853-855) e as presentemente citadas neste estudo. Na descrição morfológica foram utilizadas as terminologias adotadas por Sancho et al.(2006). Para as ilustrações foram utilizados lupa binocular QUIMIS 766 com câmara clara acoplada. As fotos foram obtidas no local de ocorrência da espécie, com máquina fotográfica Sony DSC-HX300. Em todos os locais de ocorrência da espécie foram registradas as coordenadas geográficas de cada sítio, com aparelho GPS (Sistema de Posicionamento Global) GarmimeTrex 30, com precisão de três metros. Em laboratório, utilizandose do Software GPS TrackMaker Professional, GTM PRO, versão 4.8 (desenvolvido por Odilon Ferreira Júnior), todas as coordenadas registradas em campo foram lançadas em uma base cartográfica regional, previamente seleci- 
onada e determinada a partir da Base Cartográfica Vetorial Contínua do Rio Grande do Sul (Hasenack \& Weber, 2010). Com a compilação destes dados, juntamente com as informações levantadas em campo, elaborou-se o mapa de localização geográfica dos locais de ocorrência da espécie em questão. Por fim, este mapa, gerado em arquivo formato GTM (GPS TrackMaker), foi transformado em arquivo formato Autocad DXF (DrawingInterchangeFormat/Drawing Exchange Format) e transferindo ao software Corel DRAW X5 (Software desenvolvido pela Corel Corporation, 2010), para a edição gráfica final.

\section{RESULTADOS E DISCUSSÕES}

Microgyne Marchesiana Bonifacino \& Sancho (Figura 1, 2 e 3).

Protólogo em: Systematic Botany 31: 853. 2006. TIPO: URUGUAY. Tacuarembó: Cuchilla de Laureles, 31²1'3" S, 55'59'4" W, 2 Oct 2004, J. M. Bonifacino, E. Marchesi, L. Bernardiet G. Jolochín 1178 (holótipo: MVFA!).

Descrição Botânica: Ervas perenes ramificadas com caules eretos, $8-20 \mathrm{~cm}$ de altura. Folhas alternas, de contorno oblanceolado, $10-16 \times 1.5-2.5 \mathrm{~mm}$, cobertas por tricomas filiformes e glandulares, ápice obtuso, margem profundamente pinatífida, com 3-4 pares de lóbulos, com ápice obtuso a levemente agudo, margem atenuada, decurrente; as superiores, gradativamente menores e com menos lóbulos. Capítulos solitários, radiados, pedunculados no ápice dos ramos. Invólucro de 6-8.5 × 4-5 mm; brácteas involucrais dispostas em 2-3 séries; as externas de 3-4 ×0.7-1 mm; as internas com 3.5$4 \times 0.8-1 \mathrm{~mm}$. Flores dimorfas, as marginais pistiladas, liguladas, tubo de $2.5-3 \mathrm{~mm}$, lígula de 2.5-3 mm; flores do disco com corola 5denteada no ápice, dentes de 0.8-1 mm, papilosos. Cipselas de $2-4 \times 0.8-1 \mathrm{~mm}$. Papilho escabroso, com 4-5 mm, por vezes com algumas cerdas menores.

Fenologia: Espécimes com flores e frutos foram encontradas entre Outubro e Dezembro.
Distribuição e habitat: Conforme Sancho et al. (2006), Microgyne Marchesiana é reconhecida como endêmica da Cuchilla de Laureles, departamento de Tacuarembó, Uruguai.Tendo por base as novas coletas, a sua distribuição geográfica estende-se até a localidade de Cerro Chato, no município de Santana do Livramento. Trata-se de espécie típica de afloramentos rochosos, com populações de escassos indivíduos que crescem em fissuras de afloramentos basálticos, freqüientemente associada à Sommerfeltia spinulosa Less. (Asteraceae), Sellaginella sellowii Hieron. (Selaginellaceae) e Frailea pumila Britton \& Rose (Cactaceae) (Figura 2, 3).

Conservação: Microgyne Marchesiana possui distribuição geográfica inferior a $1000 \mathrm{~km}^{2}$; as populações, de poucos indivíduos, têm habitat especializado, pois ocorrem exclusivamente em fendas de afloramentos rochosos. De acordo com os critérios da IUCN (2012), a espécie deve ser considerada "Em Perigo": EN B1a, b (iii) + 2a, b(iii).

Comentários: Por suas folhas contendo 2-4 lóbulos, Microgyne Marchesiana facilmente separa-se de $M$. trifurcata Less., que possui folhas trifurcadas. Características adicionais para a separação das espécies incluem as cipselas, com paredes mais espessas, e o papilho, esbranquiçado na maturidade (vs. rosado ou avermelhado).

Material examinado. Brasil. Rio Grande do Sul: Santana do Livramento, Cerro Chato, entre rochas, 3050'02"S, 55 34'49'O, 14/11/ 2013, L. P. Deble 14444, A. S. de Oliveira-Deble $\&$ B. P. Moreira; idem, 30 56'59"S, 5540’29”O, 14/11/2013, L. P. Deble 14445, A. S. de Oliveira-Deble \& B. P. Moreira.

\section{CONCLUSÕES}

Foi constatada a ocorrência de Microgyne Marchesiana no município de Santana do Li- 


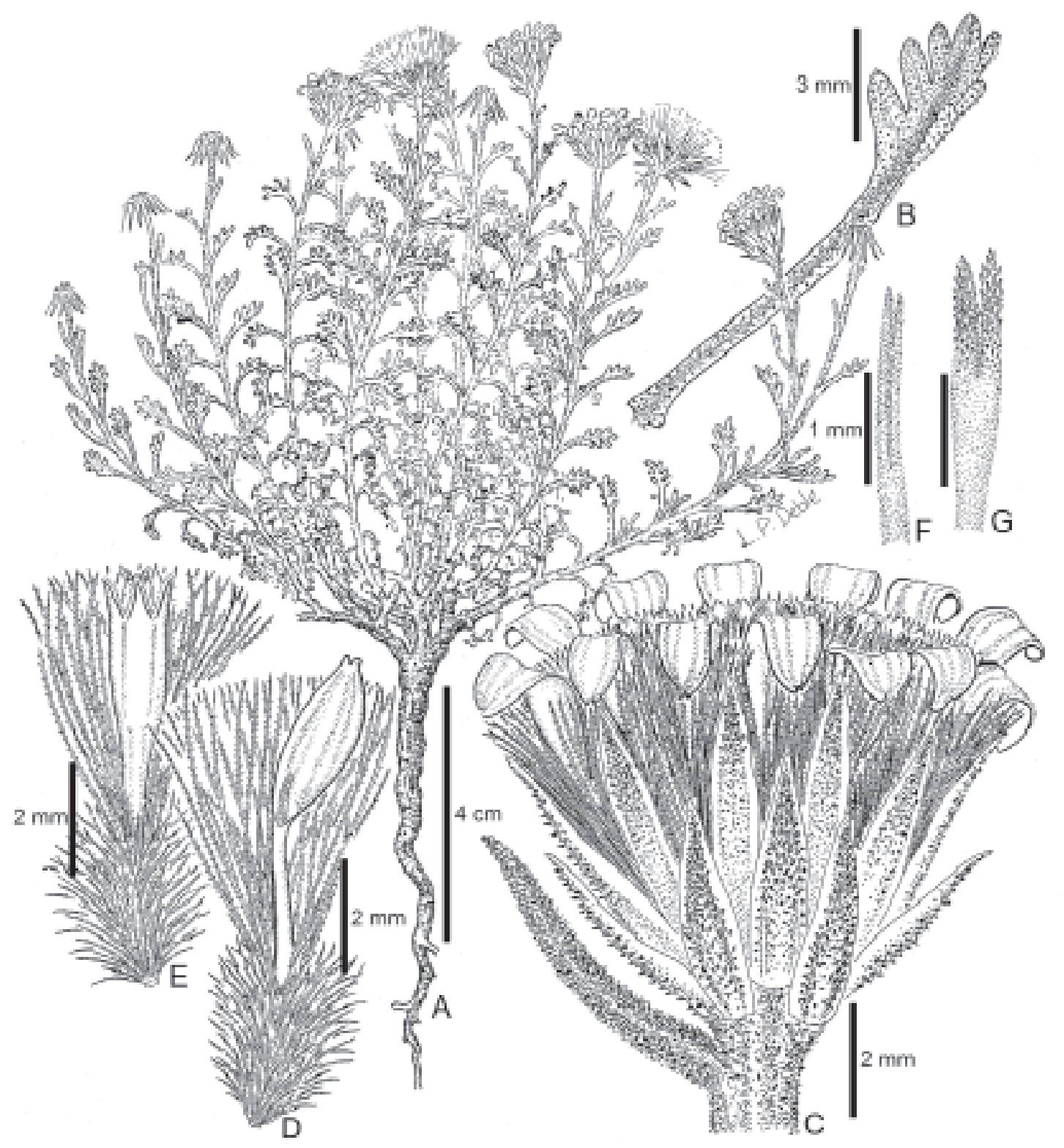

FIGURA 1 - Microgyne Marchesiana. A - Hábito. B - Folha. C - Capítulo. D - Flor pistilada. E - Flor do disco. F - Ápice do estilete da flor pistilada; G - Ápice do estilete da flor do disco (A - G de L. P. Deble 14444, A. S. de Oliveira-Deble \& B. P. Moreira). 


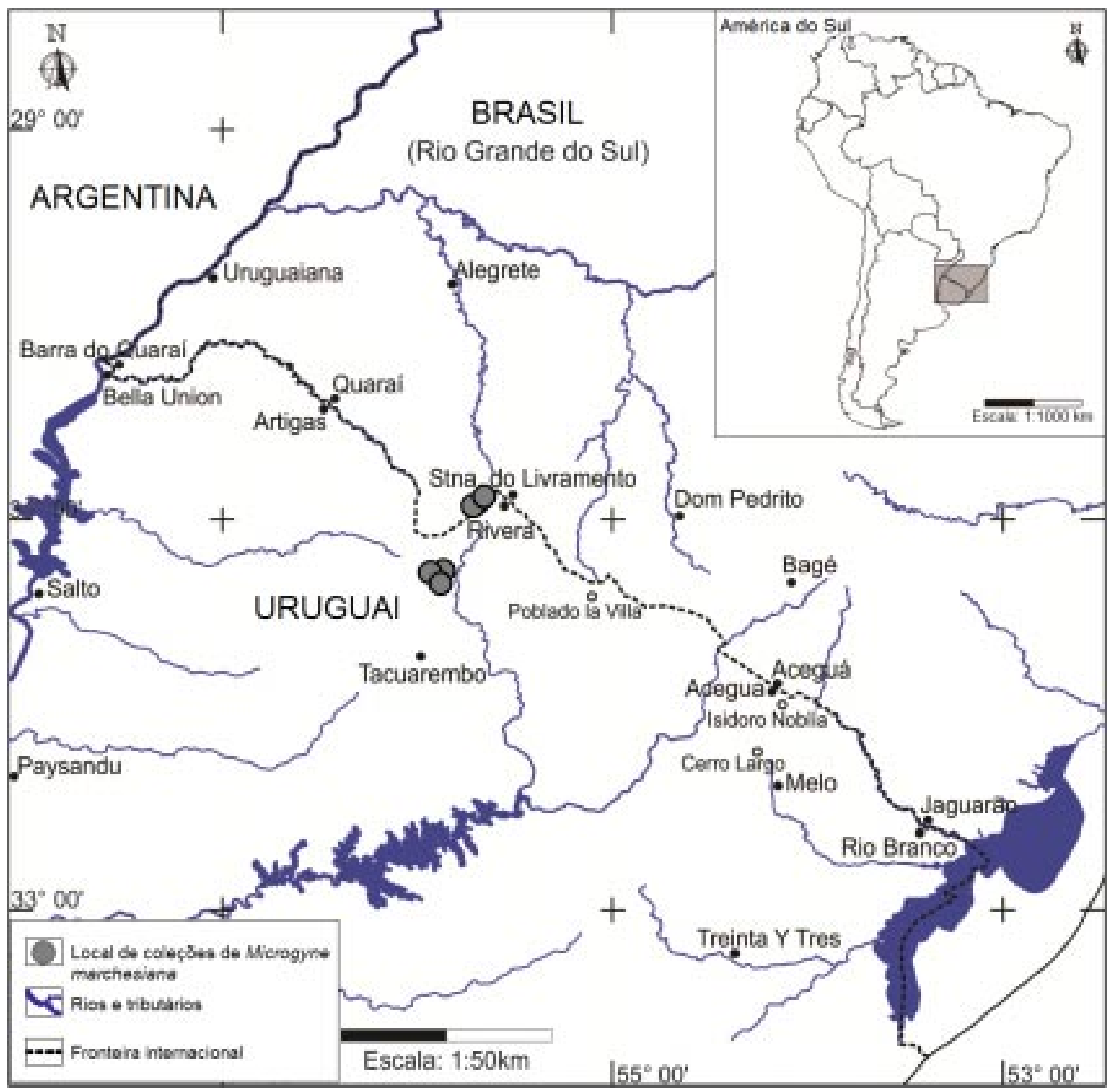

FIGURA 2 - Distribuição geográfica de Microgyne Marchesiana. 


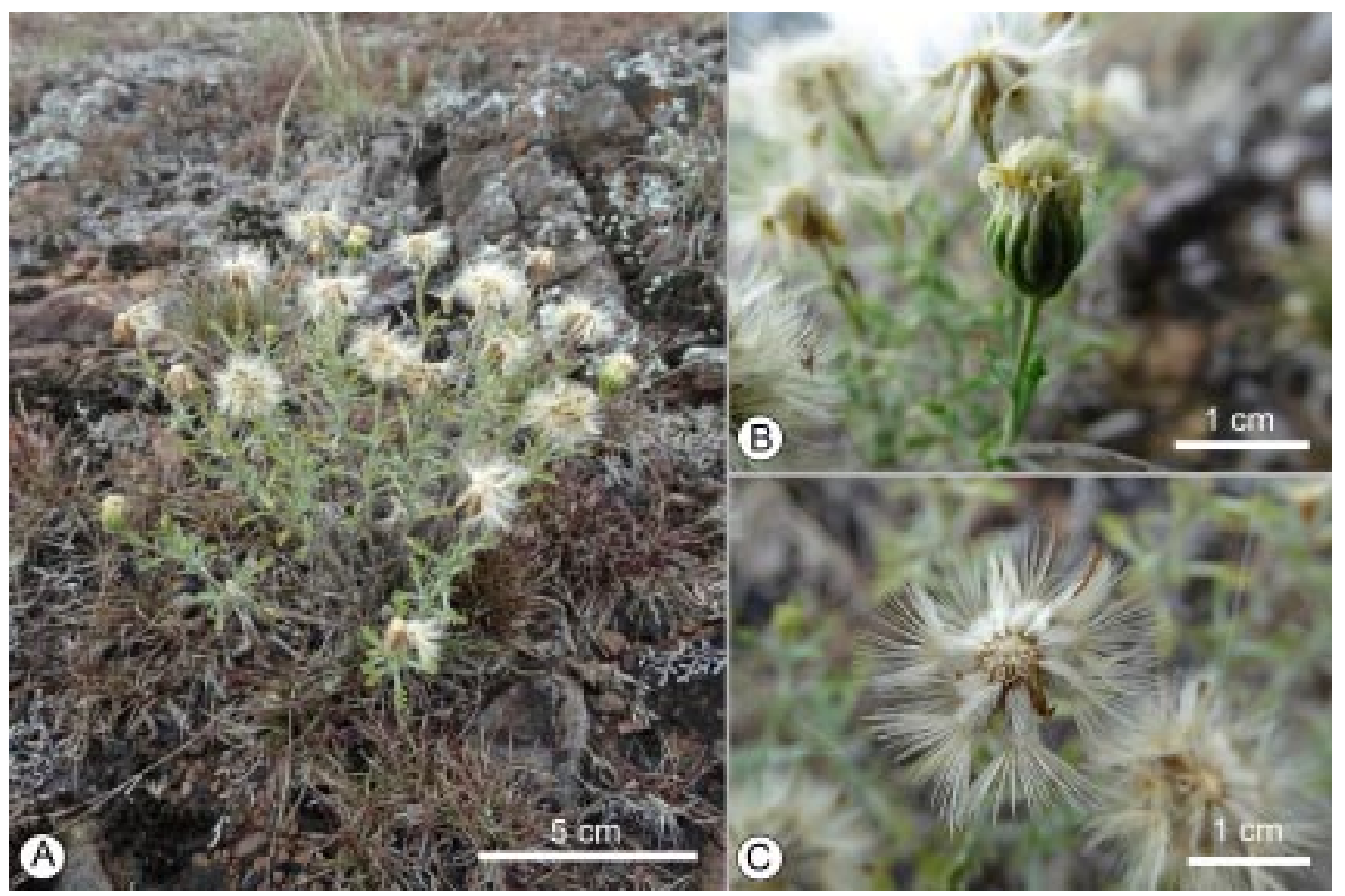

FIGURA 3 - Microgyne Marchesiana. A - Hábito. B - Capítulo. C - Capítulo com cipselas maduras (A - C de L. P. Deble 14444, A. S. de Oliveira-Deble \& B. P. Moreira).

vramento, RS, Brasil, sua presença é considerada rara, tendo sido encontrada somente duas populações, ambas representadas por poucos indivíduos, que crescem em fendas de afloramentos rochosos de origem vulcânica. Com base nas informações obtidas, a espécie foi classificada como "Em Perigo", de acordo com os critérios da IUCN. O registro deste táxon reforça a necessidade de conhecimento, conservação e distribuição geográfica da flora nativa, para tornar possível a proteção e a preservação de espécies possivelmente ameaçadas.

\section{REFERÊNCIAS BIBLIOGRÁFICAS}

ARECHAVAlETAE, J. Flora Uruguaya III: Compuestas. Anales del Museo Nacional de Montevideo 6, p. 88-503, 1907 [1908].
BAKER, J. G. Compositae: III. Asteroideae. Flora brasiliensis. Vol. 6, part 3. ed. C. F. P. Martius, München: Wien, Liepzig, p. 1-100, 1882.

BENTHAM, G. Compositae, p. 447-680. In: Flora australiensis.Vol. 3. London Reeve and Co., 1867.

BENTHAM, G.; HOOKER, J. D. Compositae. Genera plantarum. Vol. 2, part 1. London Reeve and Co., p. 163-533, 1873.

CABRERA, Á. L. Compositae. p. 106-538. Flora Ilustrada de Entre Ríos. Vol. 6, ed A. Burkart, Buenos Aires: Instituto Nacional de Tecnología Agropecuaria, 1974.

DEBLE, L. P.; OLIVEIRA-DEBLE, A. S. Asteraceae Bercht \& J. Presl (Compositae) no Rio Grande do Sul. Ciência \& Ambiente, UFSM: Santa Maria, n. 42, p. 93-112. 2011.

FORTES, A. B. Compêndio de geografia geral do

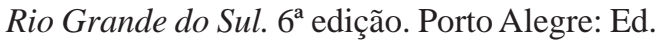
Sulina, 97 p., 1979. 
GRAU, J. Podocoma und Vittadinia, Zwei vermeintlich Bikontinentale Gattungen. Mitteilungen der Botanisch em Staatssammlung, München, n. 12, p. 181-194, 1975.

HASENACK, H.; WEBER, E. Base cartográfica vetorial contínua do RioGrande do Sul - escala 1:50.000. Porto Alegre, UFRGS-IB - Centro de Ecologia. 2010. 1 DVD-ROM (Série Geoprocessamento, 3).

IUCN (International Union for Conservation of the Nature), Categories and Criteria.The IUCN Red List of Threatened Species.http://www.iucnredlist.org/technical-documents/categories-andcriteria/. 2012. Acesso em 04/2014.
NESOM, G. L. Subtribal classification of the Astereae (Asteraceae). Phytologia, n.76, p. 193-214.1994.

OLIVEIRA-DEBLE, A. S.; DEBLE, L. P. Diversidade da família Asteraceae Bercht \& J. Presl (Compositae Giseke) no Bioma Pampa. Bioma Pampa: Ambiente $\times$ Sociedade, p. 54-67, 2012. SANCHO, G.; BONIFACINO, J. M.; PRUSKI, J. F. Revision of Microgyne (Asteraceae-Astereae), the Correct Name for Microgynella. Systematic Botany vol. 31, n. 4, p. 851-861, 2006.

THIERS, B. [atualizado continuamente]. Index Herbariorum: A global directory of public herbaria and associated staff.New York Botanical Garden's Virtual Herbarium.http://sweetgum.nybg.org/ih/. 